\title{
Epidemiology of gonorrhoea and syphilis in New Zealand
}

\author{
W. M. PLATTS \\ From the Department of Health, Christchurch, New Zealand
}

\section{Introduction}

New Zealand is a narrow, isolated country of two main islands covering 1000 miles of latitude. Over half of its 2100000 population live in the northern half of the north island near Auckland, its biggest city of 750000 people.

Of the population $9.8 \%$ are Maoris and $2 \%$ are Polynesians fairly recently arrived from the Pacific Islands; again, most are concentrated in the warmer north.

Integration of the venereal disease services on the British pattern began in 1964, and there are now 13 clinics run as outpatient services by hospital boards. More clinics, however, are needed. All are staffed by part-time venereologists, seven of whom have taken the Liverpool or London Diploma using a government award scheme. There is a contacttracing service using health department nurses, two of whom are based at their respective clinics.

A yearly meeting of medical public health and laboratory personnel concerned with venereology and sponsored by the health department has been held since 1964; furthermore, a three-week polytechnic training course for venereal disease clinic workers has just been started. Undergraduate teaching is poor, although most medical students are now rostered to attend clinics for practical instruction. Didactic instruction is minimal.

A 'dial-a-VD' service now operates in 10 cities and is being extended, but in general much more could be done in the sphere of public education.

As in the UK, venereal disease is not notifiable, but infectious syphilis is being voluntarily notified by private laboratories. Sexual contacts in New Zealand can be compulsorily examined, a law which is seldom put into practice. Methods have been standardised with full investigations and follow up, according to the standards recommended in British clinics. Laboratory standards in New

Address for reprints: Dr W. M. Platts, Department of Venereology, Christchurch Hospital, Christchurch, New Zealand

Received for publication 1 August 1978
Zealand are high, with quality control being exercised from a reference laboratory.

Gonorrhoea treatment schedules are based on a single injection of $2 \cdot 2$ megaunits of fortified procaine penicillin with probenecid, which has resulted in very few failures at present. Antibiotics are obtained by prescription only, and the use of spectinomycin is confined to clinics and only used for $\beta$-lactamaseproducing isolates and some patients who are hypersensitive to penicillin. Up to March 1978 16 isolates (12 proved) producing $\beta$-lactamase had been reported; these were mostly from patients from the Far East, but no sexual contacts were found. This figure compares with a total of 37 cases found in Australia up to October 1977, 14 being from the Far East (personal communication).

\section{Syphilis}

INCIDENCE

The incidence of infectious syphilis is at present low in New Zealand (2.8 per 100000 population, a total of under 100 cases a year). It is mostly introduced by visitors from overseas, but local outbreaks among urban homosexual groups have occurred; since both of these groups are growing an increase in cases of infectious syphilis is likely in the future.

Most adults from the Pacific islands have had yaws and were treated in 1958 and 1962 by the World Health Organisation. Infectious syphilis has recently appeared among them, however, and indicates a disappearance of their immunity.

\section{Gonorrhoea}

\section{INCIDENCE}

All diagnosed cases of gonorrhoea (clinic cases together with those referred by general practitioners via private laboratories) in New Zealand totalled 6482 in 1976, a rate of 208 per 100000 population; however, the cases seen by general practitioners and not diagnosed could swell this total by a further $25 \%$ at least. 
Of the total number of diagnosed cases throughout the country $50 \%$ are now seen in clinics, a figure which would be much higher if the clinic facilities in our biggest city, Auckland, were brought into line with the other three cities.

As has happened in many European countries, the upward trend in the incidence of gonorrhoea has fallen over the past two years (Fig. 1), the male-female ratio having remained steady at about 1·75:1 (Fig. 2). Recidivists are not a great problem in New Zealand clinics and attendances for surveillance are reasonable.

Gonococcal ophthalmia is uncommon, but pelvic inflammatory disease (PID) is common, comprising $19 \%$ of all female cases seen at the Christchurch clinic in 1977. Most of these cases were gonococcal.

Disseminated gonococcal infection is rare. Most cases, therefore, are being missed and presumably cured by routine antibiotic treatment in medical wards, which indicates the sensitivity of the gonococcus in this condition.

\section{SCREENING AND SURVEYS}

Routine screening for gonorrhoea is practised in some public obstetric and gynaecological clinics, in women's prisons, in all child welfare girls' homes, and, experimentally, in one family planning association clinic. The yield of positive results in the latter clinic is $0.5 \%$ from 2402 women seen over six months; one half of these were married, the other half single.

A large survey at the Christchurch Women's Hospital obstetric and gynaecological clinics, in

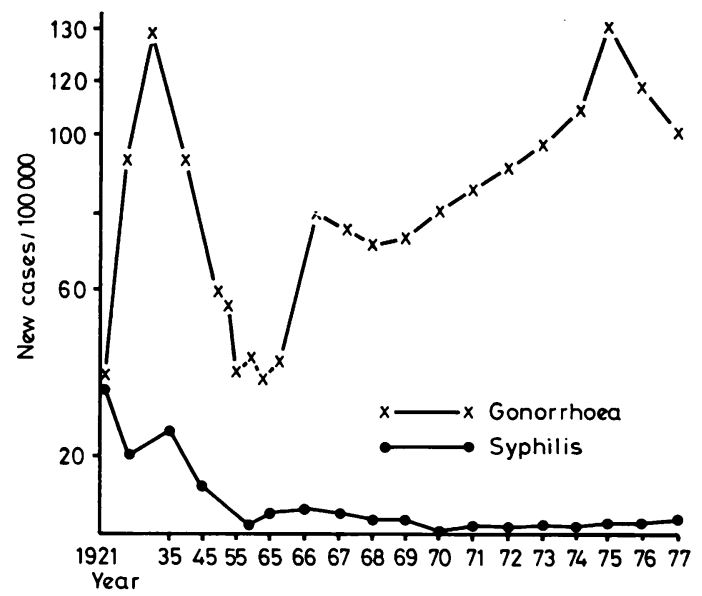

Fig. 1 Incidence of gonorrhoea and syphilis from 1921 to 1977 in New Zealand clinics (from 1971 rate for infectious syphilis only is shown)

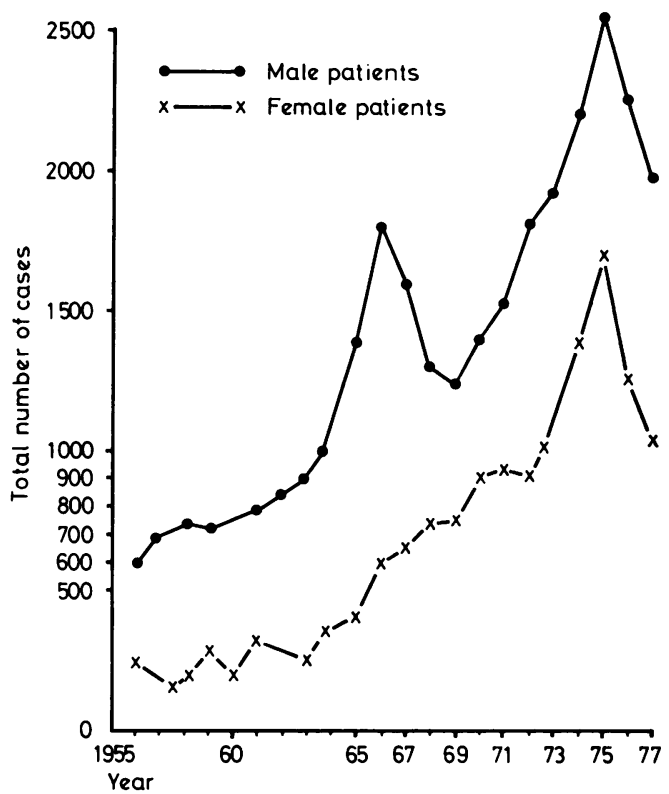

Fig. 2 Total number of male and female cases of gonorrhoea from 1955 to 1977 in New Zealand clinics

which 3389 cases were examined between 1970 and 1973 (Platts and Cresswell, 1974), yielded a positivity rate of $2.4 \%$ among the so-called 'single' group (that is, both unmarried or separated women) and a rate of $0.7 \%$ among the married group. Since then surveys have shown lower rates, but the decline may be due to technical problems.

Gonococcal sensitivities have been monitored since 1967. Initially relatively high values were obtained owing mainly to technical problems. From 1971 to 1975 the minimum inhibitory concentrations (MICs) were low but in 1976 and 1977 there was an unexplained slight rise. In $197726.6 \%$ of 2271 isolates had an MIC $>0 \cdot 1 \mathrm{IU} / \mathrm{ml}$ (Fig. 3).

\section{Other sexually transmitted diseases (STDs)}

\section{NON-SPECIFIC URETHRITIS}

The ratio of cases of non-specific urethritis (NSU) to male cases of gonorrhoea is $1 \cdot 7: 1$, the upward trend levelling out for the first time in 1977 (Fig. 4). Recurrences due to relapse or reinfection are high ( $40 \%$ in one series over a year). NSU is the commonest STD infection found among university students. The large number of young men, many of whom return again and again and require timeconsuming counselling to avert an anxiety state, comprise a serious STD problem in New Zealand today. 


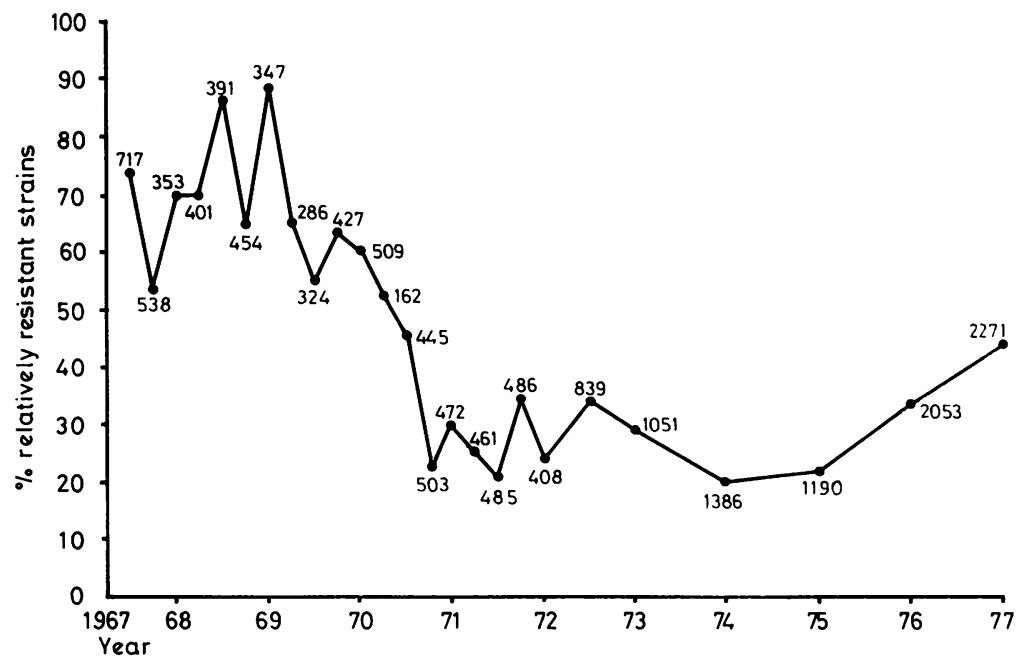

Fig. 3 Penicillin resistance of gonococci in New Zealand. (Relatively resistant strains mean strains with an MIC of $>0 \cdot 1$ units of penicillin per ml.) (The numbers give the total numbers of strains tested each year.)

Most sexual contacts of NSU are examined and treated epidemiologically, since there is no laboratory service for the culture of Chlamydia in the country yet.

\section{GENITAL HERPES AND GENITAL WARTS}

The two viral diseases, genital herpes and genital warts, have become increasingly common over the last few years and show no sign of waning. They are time-consuming and demanding to treat. A viral culture service is available but there are often delays in obtaining results.

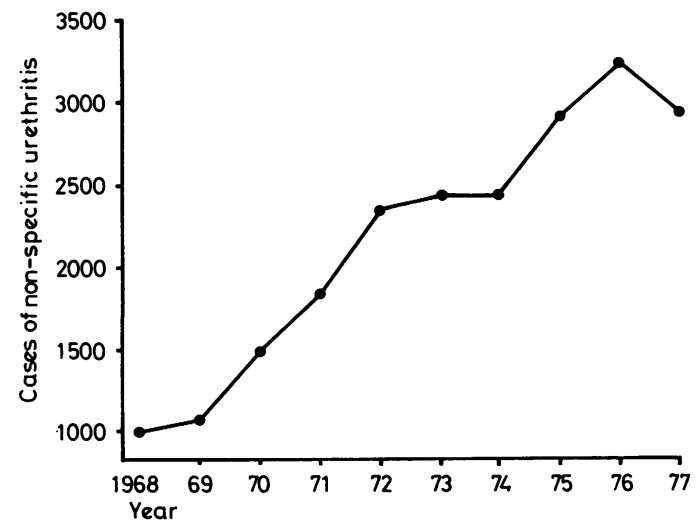

Fig. 4 Total number of male cases of non-specific urethritis from 1968 to 1977 in New Zealand clinics
TRICHOMONIASIS AND CANDIDOSIS

Trichomoniasis is relatively uncommon in New Zealand $(4 \%$ in a large survey of obstetric and gynaecological clinic patients) whereas the incidence of candidosis (at $21 \%$ in the same series) is comparable to overseas figures.

\section{HEPATITIS B}

Sexually transmitted hepatitis B has been found in patients attending clinics (Stringer et al., 1978) but cytomegalovirus has not yet been sought.

The minor types of STD are now being routinely reported from all clinics in New Zealand, the rates comparing closely with those given for England in 1975 (Department of Health and Social Security, 1978) (Table 1).

Table 1 Incidence of 'minor' sexually transmitted diseases in New Zealand clinics in 1977 compared with that in England in 1975

\begin{tabular}{lll}
\hline & \multicolumn{2}{l}{ Rate per 100000 population } \\
\cline { 2 - 3 } Diagnosis & $\begin{array}{l}\text { New Zealand } \\
(1977)\end{array}$ & $\begin{array}{l}\text { England } \\
(1975)\end{array}$ \\
Non-specific urethritis (male & & \\
patients) & 300 & 306 \\
Candidosis (female patients) & 79.6 & 75.5 \\
Trichomoniasis (female patients) & 37.5 & 77.03 \\
Genital warts & $27 \cdot 3$ & 43.38 \\
Herpes genitalis & 20.0 & 13.38 \\
Pubic lice & 14.7 & 11.01 \\
Scabies & 6.6 & 6.02 \\
Molluscum contagiosum & 3.5 & 1.62 \\
\hline
\end{tabular}


Epidemiology

'AT RISK' GROUPS

Age

Between $50 \%$ and $60 \%$ of female and $25 \%-30 \%$ of male patients attending clinics are teenagers. The number of schoolgirls has increased from $3 \%$ to $17 \%$ over the last six years at the Christchurch clinic (Table 2).

In a recent survey of 1300 clinic attenders and controls from a polytechnic college, three-quarters of the male patients attending the clinic and over half of the female patients stated that they had first had sexual intercourse aged 16 or younger as did half the male controls. The survey also showed that clinic attenders, especially the girls, left school at a younger age with a lower grading (nearly $50 \%$ at 16 or younger at fourth form level or lower) and that they were more likely to come from broken homes.

Table 2 Incidence of gonorrhoea in New Zealand clinics in 1977 by age group

\begin{tabular}{lcc}
\hline & \multicolumn{2}{c}{ Rate per 100000 population } \\
\cline { 2 - 3 } Age group (years) & Male & Female \\
\hline $10-14$ & $4 \cdot 8$ & 21 \\
$15-19$ & 471 & 557 \\
$20-24$ & 744 & 339 \\
$25-29$ & 535 & 225 \\
$30-39$ & 160 & 0 \\
\hline
\end{tabular}

\section{Occupation}

The bands of seasonal workers that move about the country-mixed shearing gangs of over 100, fruit pickers, hydroelectric engineering project workers, also female tourist hotel workers-many of whom are often itinerant and come from Australia, are high risk groups and because of often being out of reach of clinics pose a control problem. Groups of female 'shippies', mostly Maori, accompany over- seas ships from one port to another; they have a high infection rate and are hard to trace.

Prostitution, which has never before been a social problem in New Zealand-(reputedly) because of the numbers of enthusiastic amateurs-has started on a large scale in the four main centres under the guise of massage parlours with telephone call-out services. Already, many of these girls are becoming infected.

\section{Ethnic groups}

The venereal disease rate among Maoris and Polynesians is two to four times that among whites.

\section{Homosexuals}

As increasing numbers of male patients attending clinics are found to be homosexuals, the extent of their involvement in the transmission of sexually transmitted diseases is becoming clearer.

\section{Conclusion}

A venereal disease service on the British model has been operating over the past 14 years in New Zealand. Despite the fee-for-service method of payment of the general practitioner-which places him in direct competition with the clinic for patients - the system has accomplished a great deal and clinics now see two-thirds of the total number of diagnosed cases of gonorrhoea. There are still a great number of defects to be remedied, but providing interest and keenness in the specialty can be stimulated in our students and younger graduates, its modest success will continue.

\section{References}

Department of Health and Social Security (1978). Sexually transmitted diseases. British Journal of Venereal Diseases, 54, 57-59.

Platts, W. M., and Cresswell, B. (1974). Australian and New Zealand Journal of Obstetrics and Gynecology, 14, 4, 191-195.

Stringer, H. C. W., Smith, E. R., and Stewart, A. C. (1978). New Zealand Medical Journal, 87, 44-46. 